\title{
Detection of the B"-GWGR variant in the southernmost region of Brazil: unveiling the complexity of the human immunodeficiency virus-1 subtype B epidemic
}

\author{
Dennis Maletich Junqueira ${ }^{1,2}{ }^{+}$, Rúbia Marília de Medeiros ${ }^{1,2}$, \\ Thaysse Cristina Neiva Ferreira Leite ${ }^{3}$, Monick Lindenmeyer Guimarães ${ }^{3}$, \\ Tiago Gräf ${ }^{1,4}$, Aguinaldo Roberto Pinto ${ }^{4}$, Sabrina Esteves de Matos Almeida ${ }^{1}$
}

${ }^{1}$ Centro de Desenvolvimento Científico e Tecnológico, Fundação Estadual de Produção e Pesquisa em Saúde, Porto Alegre, RS, Brasil
2Programa de Pós-Graduação em Genética e Biologia Molecular, Universidade Federal do Rio Grande do Sul, Porto Alegre, RS, Brasil
'Laboratório de AIDS e Imunologia Molecular, Instituto Oswaldo Cruz-Fiocruz, Rio de Janeiro, RJ, Brasil
4Laboratório de Imunologia Aplicada, Departamento de Microbiologia, Imunologia e Parasitologia,
Centro de Ciências Biológicas, Universidade Federal de Santa Catarina, Florianópolis, SC, Brasil

Typical human immunodeficiency virus-1 subtype B (HIV-1B) sequences present a GPGR signature at the tip of the variable region 3 (V3) loop; however, unusual motifs harbouring a GWGR signature have also been isolated. Although epidemiological studies have detected this variant in approximately 17-50\% of the total infections in Brazil, the prevalence of B"-GWGR in the southernmost region of Brazil is not yet clear. This study aimed to investigate the C2-V3 molecular diversity of the HIV-1B epidemic in southernmost Brazil. HIV-1 seropositive patients were analysed at two distinct time points in the state of Rio Grande do Sul (RS98 and RSO8) and at one time point in the state of Santa Catarina (SC08). Phylogenetic analysis classified 46 individuals in the RS98 group as HIV-1B and their molecular signatures were as follows: $26 \%$ B"-GWGR, $54 \%$ B-GPGR and $20 \%$ other motifs. In the RS08 group, HIV-1B was present in 32 samples: $22 \%$ B"-GWGR, 59\% B-GPGR and 19\% other motifs. In the SC08 group, 32 HIV-1B samples were found: $28 \%$ B"'-GWGR, $59 \%$ B-GPGR and $13 \%$ other motifs. No association could be established between the HIV-1B V3 signatures and exposure categories in the HIV-1B epidemic in RS. However, B-GPGR seemed to be related to heterosexual individuals in the SC08 group. Our results suggest that the established B"-GWGR epidemics in both cities have similar patterns, which is likely due to their geographical proximity and cultural relationship.

Key words: HIV - subtype B - B”-GWGR - southernmost Brazil - molecular epidemiology

The third hypervariable region 3 (V3) of the human immunodeficiency virus-1 (HIV-1) gp120 protein consists of 35 amino acids and plays an important role in viral infection by promoting the interaction between the virus and its co-receptor in the host membrane (Hwang et al. 1991). Despite the recognised potential of HIV-1 to escape from neutralising antibodies through the extensive variability of its viral envelope glycoproteins, especially gp120, it is well known that the four amino acids at the tip of the V3 loop are subjected to strong purifying selection pressure due to their functional importance (Kwong et al. 2002, Liu et al. 2008). Although the vast majority of HIV-1 sequences present a GPGX signature at this position regardless of subtype, unusual patterns have been reported around the world (Shimizu et al. 1992, Brown et al. 1996, Kim et al. 1999, Leal \& Villanova 2010).

doi: 10.1590/0074-0276108062013010

Financial support: FAPESC, CNPq, FIOCRUZ

+ Corresponding author: dennismaletich@hotmail.com

Received 1 April 2013

Accepted 26 June 2013
Subtype B is the most geographically widespread variant of HIV-1 (HIV-1B) (Hemelaar 2012). The pandemic form of subtype B, which is prevalent in European, American and Asian countries, is typically characterised as having a GPGR motif (B-GPGR) at the tip of the V3 loop. However, several molecular studies have shown that various genetically and antigenically distinct V3 motifs, which are diversified particularly at the second position of the tetramer, co-circulate in the HIV-1B epidemic (Shimizu et al. 1992, Morgado et al. 1994, Candotti et al. 1999, Kim et al. 1999, Leal et al. 2008, Franca et al. 2011). In particular, some strains have been found to harbour an alternative signature in which the second residue of the tetrapeptide, proline, is substituted with tryptophan (B"-GWGR) (Potts et al. 1993, Casseb et al. 1998, 2002, Morgado et al. 1998, Santoro-Lopes et al. 2000, Brito et al. 2006, Araujo et al. 2010, Franca et al. 2011). Clinical studies support the hypothesis that the B"-GWGR motif is correlated with slower disease progression in infected patients when compared with those infected with the B-GPGR variant (Santoro-Lopes et al. 2000, Brito et al. 2006, Araujo et al. 2010).

Brazil is accepted as the epicentre of the B"-GWGR epidemic (Diaz et al. 2008, Pinto et al. 2008). While viruses presenting this motif are sporadically observed in other countries, several studies in Brazil have found this variant at frequencies ranging from $17-50 \%$ (Morgado et 
al. 1994, Casseb et al. 1998, Araujo et al. 2010, Franca et al. 2011). Despite these results, recent findings about the temporal trends of the B"-GWGR epidemic in this country suggest a decline in the prevalence of this variant (Araujo et al. 2010, Franca et al. 2011). Several studies have highlighted the complexity of the HIV-1 epidemic in the southernmost region of Brazil, where subtype C, subtype B and several recombinant forms have been detected (Soares et al. 2003, Santos et al. 2006, de Medeiros et al. 2011, Gräf et al. 2011, Gräf \& Pinto 2013), but no studies have attempted to detect B"-GWGR in this region. The current extent of the B"-GWGR epidemic in Brazil remains an unresolved question. Thus, the present study aims to investigate the molecular diversity of the HIV-1 subtype B epidemic in distinct exposure categories in the southernmost region of Brazil.

\section{SUBJECTS, MATERIALS AND METHODS}

The present study investigated 278 samples from three distinct groups of HIV-1-positive individuals from various outpatient clinics in the southernmost region of Brazil. The first group (RS98) contained 83 blood samples that were obtained from HIV-1-positive individuals recruited from a health reference centre in Porto Alegre, the capital city of the state of Rio Grande do Sul, in 1998. The second group (RS08) was comprised of 97 samples from HIV-infected individuals that were collected in Porto Alegre between 2005-2008. The third group (SC08) was composed of blood samples that were collected from 98 HIV-positive patients at follow-up appointments at a reference centre in the city of Florianópolis, the capital city of the state of Santa Catarina, between 2004-2008. The demographic data of the patients included in this study were extracted from clinical records or were obtained through direct interview. All of the individuals from Porto Alegre were antiretroviral treatment-naïve, while the individuals from Florianópolis were either naïve or under antiretroviral therapy at the time of blood collection. This study was approved by the ethical committees of the institutions involved and all patients provided written informed consent.

DNA was extracted from $200 \mu \mathrm{L}$ of each whole blood sample using a QIAamp DNA kit (Qiagen, CA, USA) according to the manufacturer's protocol. The partial C2-V3 region of the env gene (nucleotides 6921-7283, relative to strain HXB2) was amplified by polymerase chain reaction (PCR) using nested primers as previously described (Delwart et al. 1993). The products were purified using a PureLink PCR Purification kit (Invitrogen, CA, USA) according to the manufacturer's directions. The purified DNA was sequenced using the ABI BigDye Terminator v.3.1 Cycle Sequencing Ready Reaction kit (Applied Biosystems, CA, USA) and processed with an automated ABI 3130xl Genetic Analyzer (Applied Biosystems). The sequences were edited and then aligned with reference sequences retrieved from the Los Alamos Sequence Database using CLUSTALX (Larkin et al. 2007).

Subtypes were assigned based on maximum likelihood (ML) phylogenetic reconstruction conducted on MEGA 5 software under the GTR+G+I model of nucleotide substitution (Tamura et al. 2011). A bootstrap test with 1,000 replicates was used to estimate the confidence of the branching patterns of the phylogenetic tree. The sequences were also submitted to the REGA Subtyping Tool of the BioAfrica Database to corroborate the subtypes assigned by the ML analysis.

The molecular signatures of the HIV-1 subtype B V3 loop were identified through visual inspection from amino acid positions 15-18 (nucleotides 7158-7169, relative to strain HXB2). The typical subtype B signature was identified as B-GPGR, whereas viruses harbouring the alternative $\mathrm{W}$ (tryptophan) signature were assigned as B"-GWGR. Assuming that the epidemiological, serological and clinical differences observed between the $\mathrm{B}$ and B" signatures in previous studies are accurate (Hendry et al. 1996, Santoro-Lopes et al. 2000, Casseb et al. 2002, Brito et al. 2006, Leal et al. 2008, Pinto et al. 2008), sequences presenting related motifs that retained the $\mathrm{P}$ or $\mathrm{W}$ at second position of the tetrapeptide (XPXX and XWXX) were also considered as B-GPGR or B"GWGR, respectively, because these most likely evolved from an ancestral sequence containing one of these motifs (Diaz et al. 2008). Sequences depicting an amino acid other than $\mathrm{W}$ or $\mathrm{P}$ at position 16 of the V3 loop were evaluated separately.

Statistical comparisons between and within groups were made using Pearson's $\chi^{2}$-test and Fisher's exact test when appropriate. The statistical analyses were performed using WinPepi v.11.22 (Abramson 2004) and the significance level was set at $p<0.05$. Due to their low frequency, the sequences harbouring amino acids other than $\mathrm{P}$ or $\mathrm{W}$ in the second position of the V3 loop were excluded from the statistical analyses.

\section{RESULTS}

Phylogenetic analysis of group RS98 revealed the cocirculation of four HIV-1 subtypes: B (55\%), C (39\%), F1 $(5 \%)$ and A (1\%). Of the 46 HIV-1 subtype B samples in RS98, 54\% were typed as B-GPGR, 26\% as B"-GWGR and $20 \%$ presented an amino acid other than $\mathrm{W}$ or $\mathrm{P}$ at position 16 of the V3 loop (Tables I, II). In this study, B"-GWGR viruses accounted for $15 \%$ of all of the HIV infections evaluated in Porto Alegre in 1998. Based on their medical records, the RS98 HIV-1B-infected patients were categorised according to the route of probable infection: heterosexual (HET) (50\%), men who have sex with men (MSM) (44\%), people who inject drugs (4\%) and blood transfusion (2\%). Their classification according to gender was $70 \%$ male and $30 \%$ female (Table I). The HIV-1B signatures according to the patients' gender and exposure category are shown in Table I. No association could be established between the subtype B molecular signatures and the exposure category or gender.

Of the 97 HIV-1 individuals in group RS08, 33\% were subtyped as B and $67 \%$ were subtyped as C. The subtype B V3 loop signatures were as follows: 59\% B-GPGR, $22 \%$ B"-GWGR and $19 \%$ other motifs (Tables I, II). In total, B"-GWGR was observed in $8 \%$ of all of the HIV-1 infections evaluated in Porto Alegre between 2005-2008. Regarding the exposure categories of the subtype B samples, group RS08 showed (53\%) HET (6 males and 11 females) and (31\%) MSM individuals. The exposure 
category was not determined for five individuals. No statistically significant associations between the subtype B signatures and the exposure category or gender were observed for RS08. After verifying the homogeneity of the gender and number of the individuals in each exposure category, statistical comparison based on Pearson's $\chi^{2}-$ test revealed no temporal differences between the RS98 and RS08 groups regarding the subtype B epidemic.

In group SC08, subtype B was detected in 32 samples with a differential distribution of the molecular signatures: $59 \%$ of the samples presented the B-GPGR motif, $28 \%$ presented the B"-GWGR motif and $13 \%$ presented other motifs (Tables I, II). The remaining 68\% samples were assigned as subtype C. Epidemiologically, the B"-GWGR variant was found to be responsible for approximately $9 \%$ of the total infections in Florianópolis. Regarding the risk factors for HIV-1B infection, $72 \%$ of the patients were HET ( 15 females and 8 males) and $28 \%$ were MSM. Similar distributions of the HIV1B molecular signatures were observed in Porto Alegre (RS08) and Florianópolis (SC08) during the same time period. A statistically significant association $(p=0.035)$ was observed between the HET exposure category and the B-GPGR variant in the $\mathrm{SC} 08$ group.

Nineteen samples presented 13 different motifs that were unrelated to the B-GPGR or B"-GWGR motifs in this analysis (9 samples from RS98, 6 samples from RS08 and 4 from SC08) (Table II). In addition, six motifs that were related to the B-GPGR motif and two motifs that were related to the B"-GWGR motif were detected. Three samples from group RS98 exhibited unique motifs: GRGA, GRGR and RRGG.

\section{DISCUSSION}

Now present in at least 23 countries around the world (Pinto et al. 2008, Leal \& Villanova 2010), the B"-GWGR variant of HIV-1 seems to have originated in Brazil (Diaz et al. 2008, Pinto et al. 2008, Leal \& Villanova 2010) and since its isolation in the early 1990s, it has been widely studied in this country (Potts et al. 1993, Louwagie et al. 1994, Casseb et al. 1998, 2002, Morgado et al. 1998, Santoro-Lopes et al. 2000, Brito et al. 2006, Pinto et al. 2008, Araujo et al. 2010, Franca et al. 2011). However, the vast majority of studies concerning the B"GWGR motif have focused on the study of the HIV-1 epidemic in southeastern Brazil, where the prevalence of subtype B is extremely high. In addition, information about the B"-GWGR epidemic in other regions of Brazil is scarce. This is the first report of the circulation of B"GWGR viruses in the southernmost region of Brazil.

The current study shows that B"-GWGR motif-containing viruses play an important role in the HIV-1 subtype B epidemic in southernmost Brazil (Table I). Our molecular analysis of HIV-1 blood samples from Porto Alegre showed that the B"-GWGR motif was present in approximately $24 \%$ of the subtype B samples. These results revealed no significant difference in the distribution of molecular signatures within the subtype B

\section{TABLE I}

Human immunodeficiency virus-1 subtype B variable region 3 loop motifs frequencies according to patient's gender and exposure category

\begin{tabular}{|c|c|c|c|c|c|c|c|c|c|}
\hline & \multicolumn{3}{|c|}{$\begin{array}{c}\text { Group RS98 } \\
\quad(n=46)\end{array}$} & \multicolumn{3}{|c|}{$\begin{array}{l}\text { Group RS08 } \\
\quad(\mathrm{n}=32)\end{array}$} & \multicolumn{3}{|c|}{$\begin{array}{l}\text { Group SC08 } \\
\quad(\mathrm{n}=32)\end{array}$} \\
\hline & $\begin{array}{l}\text { B"-GWGR } \\
\text { and related } \\
(\mathrm{n}=12)\end{array}$ & $\begin{array}{c}\text { B-GPGR } \\
\text { and related } \\
(\mathrm{n}=25)\end{array}$ & $\begin{array}{l}\text { Other } \\
(\mathrm{n}=9)\end{array}$ & $\begin{array}{l}\text { B"-GWGR } \\
\text { and related } \\
\quad(\mathrm{n}=7)\end{array}$ & $\begin{array}{c}\text { B-GPGR } \\
\text { and related } \\
(\mathrm{n}=19)\end{array}$ & $\begin{array}{l}\text { Other } \\
(\mathrm{n}=6)\end{array}$ & $\begin{array}{l}\text { B"-GWGR } \\
\text { and related } \\
(\mathrm{n}=9)\end{array}$ & $\begin{array}{l}\text { B-GPGR } \\
\text { and related } \\
(\mathrm{n}=19)\end{array}$ & $\begin{array}{l}\text { Other } \\
(\mathrm{n}=4)\end{array}$ \\
\hline \multicolumn{10}{|c|}{ Gender $[\mathrm{n}(\%)]$} \\
\hline Male & $8(67)$ & $17(68)$ & $7(78)$ & $4(57)$ & $11(58)$ & $3(5)$ & $7(78)$ & $7(37)$ & $3(75)$ \\
\hline Female & $4(33)$ & $8(32)$ & $2(22)$ & $2(29)$ & $7(37)$ & $2(33)$ & $2(22)$ & $12(63)$ & $1(25)$ \\
\hline ND & - & - & - & $1(14)$ & $1(5)$ & $1(17)$ & - & - & - \\
\hline \multicolumn{10}{|c|}{ Exposure category $[\mathrm{n}(\%)]$} \\
\hline HET & $6(50)$ & $12(48)$ & $5(56)$ & $5(71)$ & $8(42)$ & $4(66)$ & $4(44)$ & $17(89)^{a}$ & $2(50)$ \\
\hline MSM & $5(42)$ & $13(52)$ & $2(22)$ & $1(14)$ & $8(42)$ & $1(17)$ & $5(56)$ & $2(11)$ & $2(50)$ \\
\hline PWID & $1(8)$ & - & $1(11)$ & - & - & - & - & - & - \\
\hline BT & - & - & $1(11)$ & - & - & - & - & - & - \\
\hline ND & - & - & - & $1(14)$ & $3(16)$ & $1(17)$ & - & - & - \\
\hline \multicolumn{10}{|c|}{ Prevalence (within group) (\%) } \\
\hline & 26 & 54 & 20 & 22 & 59 & 19 & 28 & 59 & 13 \\
\hline
\end{tabular}

$a$ : significant association ( $\mathrm{p}=0.035)$ between heterosexual (HET) individuals and B-GPGR motif infection; BT: blood transfusion; MSM: men who have sex with men; ND: not declared; PWID: people who inject drugs. Values in the brackets are the relative percentages according to gender or exposure category. 
epidemic between 1998-2008 and suggest that the epidemic has been stable in this city since the mid-1990s. In contrast, epidemiological studies have shown that the prevalence of B"-GWGR has been decreasing over time in other regions of Brazil (Hendry et al. 1996, Casseb et al. 1998, Brito et al. 2006, Araujo et al. 2010). B"-GWGR viruses were previously estimated (by anti-V3 serologic assay) to account for approximately $27 \%, 48 \%$ and $64 \%$ of all HIV infections from samples isolated in the 1990s in the cities of Salvador, Rio de Janeiro and São Paulo, respectively (Hendry et al. 1996). However, more recently, molecular investigations detected this motif in $18 \%$, $23 \%$ and $34 \%$ of the investigated HIV-infected individuals in the same cities in the years of 2006-2010 (Araujo et al. 2010, Arruda et al. 2011, Pimentel et al. 2011). Nevertheless, the differences observed in the other Brazilian regions could be related to the varied methods used to detect the B"-GWGR variant or could be due to the

\section{TABLE II}

Human immunodeficiency virus-1 subtype B variable region 3 (V3) motifs diversity according to the local of sample collection and year

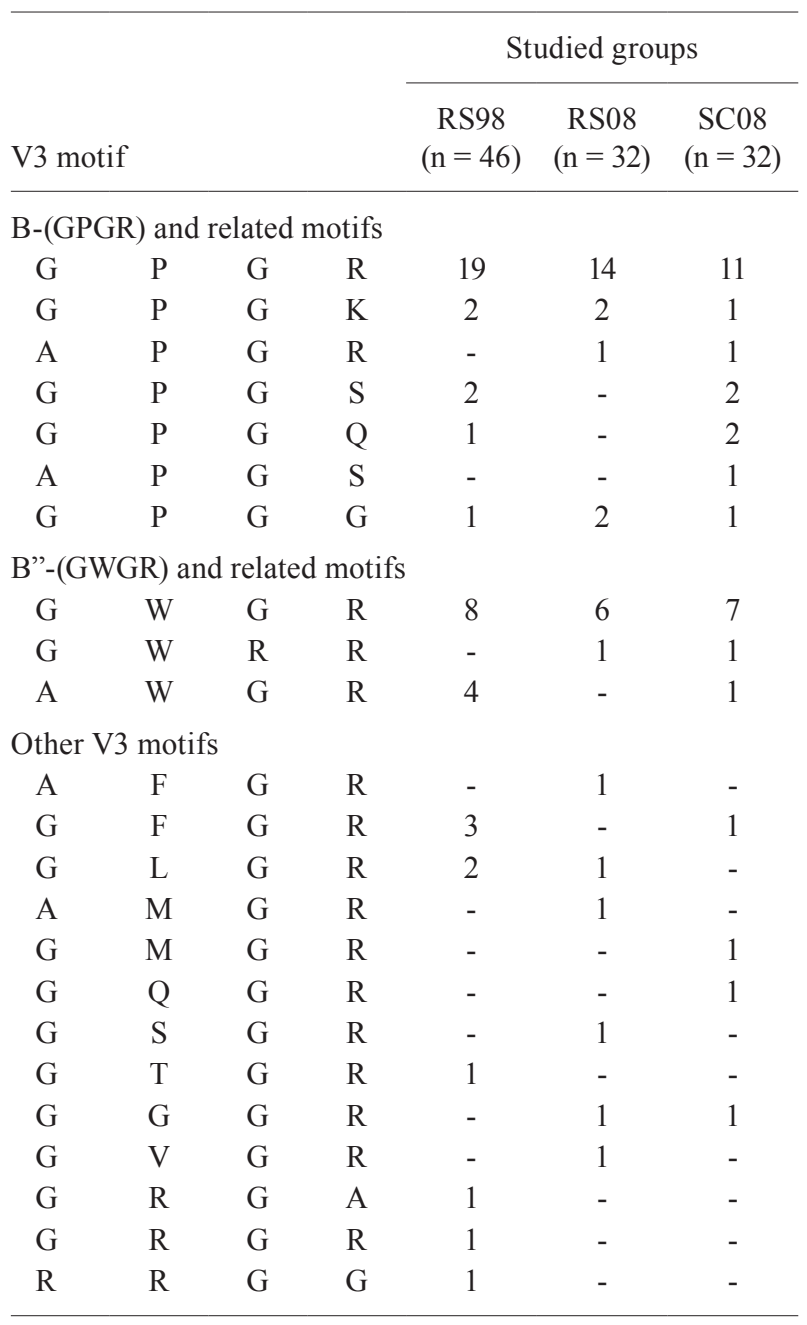

sampling of individuals from different exposure categories. In addition, the observed temporal difference in the B"-GWGR epidemic could be the result of the influence of a random effect on the local transmission networks. However, further studies that use molecular analysis to examine representative sample sizes that include individuals from the same gender, exposure category and acquired immune deficiency syndrome (AIDS) progression stage are needed to assess the temporal trends of the B"-GWGR epidemic in Brazil.

The V3 loop motifs of the viruses in the subtype B epidemic in the city of Florianópolis ( $\mathrm{SC} 08)$ were not significantly different from those of the epidemic in Porto Alegre (RS08) in the same time period. Moreover, due to the circulation of non-B subtypes in southernmost Brazil, especially subtype C, the B"-GWGR variant may be evaluated as part of the total epidemic. In this case, B"-GWGR was responsible for $15 \%$ and $8 \%$ of the HIV-1 infections in the years 1998 and 2005-2008 in Porto Alegre and for $9 \%$ of the HIV-1 infections in 2004-2008 in Florianópolis. Nevertheless, these results are not comparable with the results of other related studies because most of the other studies were performed in states where non-B subtypes are more infrequent and subtype B predominates (Santos et al. 2011, Alcalde et al. 2012, Pilotto et al. 2012). Taken together, our results suggest that the HIV-1 subtype B epidemics in Florianópolis and Porto Alegre have a similar pattern (Table I). The cultural relationship and the geographical proximity of Porto Alegre and Florianópolis may have influenced the dynamic of the transmission chains and could explain the similar results within these cities (Bello et al. 2012). However, comparing the entire HIV-1 epidemic in Southern (which consists of subtype C, subtype B and recombinant forms) with the HIV-1 epidemic in other states of Brazil, it seems that B"-GWGR is not as prevalent in the more southern states of Brazil.

Although many studies have attempted to unravel the origin and prevalence of the B"-GWGR variant, only one study has sought to understand the spreading pattern of this variant and its relationship with the patient's exposure category (Pimentel et al. 2011). A recent study carried out in Rio de Janeiro found that the B"GWGR variant was most likely introduced into the local epidemic by bisexual individuals (Pimentel et al. 2011). Analysis of the results for the RS98 and RS08 groups revealed no significant association between the exposure category and the V3 loop motif of HIV-1 subtype B. The lack of an association found here may be explained by the complete intermixing of local transmission chains (Almeida et al. 2012). Alternatively, this result may suggest the inexistence of V3 loop motif stratification by exposure category in the initial spread of HIV-1 subtype $\mathrm{B}$ in Porto Alegre. Although previous results have found a significant association $(p<0.05)$ between the MSM exposure category and subtype B in the 1990s (Almeida et al. 2012), our results suggest that there is no difference in regard to the V3 motifs in the subtype B epidemic in MSM and HET individuals between 1998-2008. Analysis of group SC08 suggests that the B"-GWGR motif is also not associated with any exposure category. In 
contrast, it seems that the dissemination of B-GPGR in Florianópolis is associated with the HET population. In a previous study based on the pol gene, a significant difference in the subtype distribution among distinct exposure categories in the HIV epidemic in Florianópolis was observed (Gräf et al. 2011). Together, these results suggest the existence of limited events of transmission between MSM and HET individuals due to a reduced overlap of the transmission chains in Florianópolis.

A remarkable feature of the HIV-1 epidemic in the southernmost region of Brazil is the co-circulation of subtypes B and C in high proportions (de Medeiros et al. 2011, Gräf et al. 2011, Almeida et al. 2012, Araújo et al. 2012). In addition, this region encompasses the 10 cities with the highest AIDS incidence rates in Brazil (MS 2012). This scenario becomes even more complex with the identification of a co-circulating molecular variant of subtype B that seems to have clinical particularities (Santoro-Lopes et al. 2000, Casseb et al. 2002, Brito et al. 2006, Leal et al. 2008). The GWGR motif seems to increase the avidity of V3 antibodies for the virus and contributes to slower disease progression in comparison to B-GPGR infection (Casseb et al. 2004, Brito et al. 2006). As longer periods of HIV-1 infection are expected for B"-GWGR-containing viruses, the chance of HIV-1 transmission to other individuals should be greater. Consequently, an increased number of infections caused by B"-GWGR viruses is anticipated over time in Brazil. In contrast, the increase in the avidity of $\mathrm{V} 3$ antibodies could contribute to a decrease in the viral load in B"-GWGR infected patients, thereby reducing the chances of HIV-1 transmission to new hosts and consequently decreasing the number of infections caused by this variant. The results presented here for the HIV-1 epidemic in the southernmost region of Brazil demonstrate that the number of infections caused by B"GWGR within the subtype B epidemic is not increasing, but is being maintained. Several hypotheses can explain the stabilisation of this epidemic. However, other studies assessing behavioural as well as biological and clinical data will be needed to answer these questions and predict the future of the HIV-1 epidemic in Brazil. Despite the complex HIV-1 epidemic in the southernmost region of Brazil, the frequency of B"-GWGR within subtype $\mathrm{B}$ viruses is comparable to that found in other Brazilian states. These results add another layer to the already complex HIV epidemic of southernmost Brazil and highlight the importance of surveillance studies in monitoring the dissemination of HIV-1 variants, specifically B"-GWGR, which seems to confer a differential clinical prognosis.

\section{REFERENCES}

Abramson JH 2004. WINPEPI (PEPI-for-Windows): computer programs for epidemiologists. Epidemiol Perspect Innov 1: 6.

Alcalde R, Guimarães ML, Duarte AJ, Casseb J 2012. Clinical, epidemiological and molecular features of the HIV-1 subtype C and recombinant forms that are circulating in the city of São Paulo, Brazil. Virol J 9: 156.

Almeida SEM, de Medeiros RM, Junqueira DM, Gräf T, Passaes CP, Bello G, Morgado MG, Guimarães ML 2012. Temporal dynamics of HIV-1 circulating subtypes in distinct exposure categories in southern Brazil. Virol J 9: 306.
Araujo AF, Brites C, Monteiro-Cunha J, Santos LA, Galvao-Castro B, Alcantara LCJ 2010. Lower prevalence of human immunodeficiency virus type 1 Brazilian subtype B found in northeastern Brazil with slower progression to AIDS. AIDS Res Hum Retroviruses 26: 1249-1254.

Araújo LA, Junqueira DM, de Medeiros RM, Matte MC, Almeida SE 2012. Naturally occurring resistance mutations to HIV-1 entry inhibitors in subtypes B, C and CRF31 BC. J Clin Virol 54: 6-10.

Arruda LB, Romano C, Martinez M, Araújo M, Costa F, Oliveira K, Gonsalez C, Duarte A, Casseb J 2011. The HIV-1 subtype B variant (B'-GWGR motif) was introduced by founder effect among the HIV-1-infected subjects in São Paulo city, Brazil. Proceedings of the 6th IAS Conference on HIV Pathogenesis, Treatment and Prevention, 17-20 July 2011, International AIDS Society, Rome. Available from: pag.ias2011.org/abstracts.aspx?aid=844.

Bello G, Zanotto PMA, Iamarino A, Gräf T, Pinto AR, CoutoFernandez JC, Morgado MG 2012. Phylogeographic analysis of HIV-1 subtype C dissemination in southern Brazil. PLoS ONE 7: e35649.

Brito A, Komninakis SCV, Oliveira RM, Fonseca LAM, Duarte AJS, Casseb J 2006. Women infected with HIV type 1 Brazilian variant, subtype B (B -GWGR motif) have slower progression to AIDS, compared with patients infected with subtype B (B-GPGR Motif). Clin Infect Dis 43: 1-5.

Brown TM, Robbins KE, Sinniah M, Saraswathy TS, Lee V, Hooi LS, Vijayamalar B, Luo CC, Ou CY, Rapier J, Schochetman G, Kalish ML 1996. HIV type 1 subtypes in Malaysia include B, C and E. AIDS Res Hum Retroviruses 12: 1655-1657.

Candotti D, Tareau C, Barin F, Joberty C, Rosenheim M, M'Pele P, Huraux JM, Agut H 1999. Genetic subtyping and V3 serotyping of HIV type 1 isolates in Congo. AIDS Res Hum Retroviruses 15: 309-314.

Casseb J, Hong MA, Gonsalez C, Brígido LF, Duarte AJ, MichaelHendry R 1998. Two variants of HIV-1 B serotype are transmitted heterosexually in São Paulo, Brazil. Braz J Med Biol Res 31: $1243-1246$.

Casseb J, Komninakis S, Abdalla L, Brigido L, Rodrigues R, Araujo F, Veiga AP, de Almeida A, Flannery B, Hendry RM, Duarte AJ 2002. HIV disease progression: is the Brazilian variant subtype B' (GWGR motif) less pathogenic than US/European subtype B (GPGR). Int J Infect Dis 6: 164-169.

Casseb J, Montanheiro P, Komninakis S, Brito A, Duarte AJS 2004. Human immunodeficiency virus type 1 Brazilian subtype B variant showed an increasing avidity of the anti-V3 antibodies over time compared to the subtype B US/European strain in São Paulo, Brazil. Mem Inst Oswaldo Cruz 99: 69-71.

de Medeiros RM, Junqueira DM, Matte MCC, Barcellos NT, Chies JAB, Almeida SEM 2011. Co-circulation HIV-1 subtypes B, C and CRF31-BC in a drug-naïve population from southernmost Brazil: analysis of primary resistance mutations. J Med Virol 83: 1682-1688.

Delwart EL, Shpaer EG, Louwagie J, McCutchan FE, Grez M, Rübsamen-Waigmann H, Mullins JI 1993. Genetic relationships determined by a DNA heteroduplex mobility assay: analysis of HIV-1 env genes. Science 262: 1257-1261.

Diaz RS, Leal E, Sanabani S, Sucupira MC, Tanuri A, Sabino EC, Janini LM 2008. Selective regimes and evolutionary rates of HIV-1 subtype B V3 variants in the Brazilian epidemic. Virology 381: 184-193.

Franca RF, Castro-Jorge LA, Neto RJ, Jorge DM, Lima DM, Colares JK, Paula SO, da Fonseca BA 2011. Genotypic characteristics of HIV type 1 based on gp120 hypervariable region 3 of isolates from southern Brazil. AIDS Res Hum Retroviruses 27: 903-909. 
Gräf T, Passaes CP, Ferreira LG, Grisard EC, Morgado MG, Bello G, Pinto AR 2011. HIV-1 genetic diversity and drug resistance among treatment naïve patients from Southern Brazil: an association of HIV-1 subtypes with exposure categories. J Clin Virol 51: 186-191.

Gräf T, Pinto AR 2013. The increasing prevalence of HIV-1 subtype C in southern Brazil and its dispersion through the continent. Virology 435: 170-178.

Hemelaar J 2012. The origin and diversity of the HIV-1 pandemic. Trends Mol Med 18: 182-192.

Hendry RM, Hanson CV, Bongertz V, Morgado M, Duarte A, Casseb J, Brigido L, Sabino E, Diaz R, Galvão-Castro B 1996. Immunoreactivity of Brazilian HIV isolates with different V3 motifs. Mem Inst Oswaldo Cruz 91: 347-348.

Hwang SS, Boyle TJ, Lyerly HK, Cullen BR 1991. Identification of the envelope V3 loop as the primary determinant of cell tropism in HIV-1. Science 253: 71-74.

Kim EY, Cho YS, Maeng SH, Kang C, Nam JG, Lee JS 1999. Characterization of V3 loop sequences from HIV type 1 subtype B in South Korea: predominance of the GPGS motif. AIDS Res Hum Retroviruses 15: 681-686.

Kwong PD, Doyle ML, Casper DJ, Cicala C, Leavitt SA, Majeed S, Steenbeke TD, Venturi M, Chaiken I, Fung M, Katinger H, Parren PWIH, Robinson J, Van Ryk D, Wang L, Burton DR, Freire E, Wyatt R, Sodroski J, Hendrickson WA, Arthos J 2002. HIV-1 evades antibody-mediated neutralization through conformational masking of receptor-binding sites. Nature 420: 678-682.

Larkin MA, Blackshields G, Brown NP, Chenna R, McGettigan PA, McWilliam H, Valentin F, Wallace IM, Wilm A, Lopez R, Thompson JD, Gibson TJ, Higgins DG 2007. CLUSTALW and CLUSTALX version 2.0. Bioinformatics 23: 2947-2948.

Leal E, Silva WP, Sucupira MC, Janini LM, Diaz RS 2008. Molecular and structural characterization of HIV-1 subtype B Brazilian isolates with GWGR tetramer at the tip of the V3-loop. Virology 381: 222-229.

Leal E, Villanova FE 2010. Diversity of HIV-1 subtype B: implications to the origin of BF recombinants. PLOS ONE 5: e11833.

Liu Y, Curlin ME, Diem K, Zhao H, Ghosh AK, Zhu H, Woodward AS, Maenza J, Stevens CE, Stekler J, Collier AC, Genowati I, Deng W, Zioni R, Corey L, Zhu T, Mullins JI 2008. Env length and $\mathrm{N}$-linked glycosylation following transmission of human immunodeficiency virus type 1 subtype B viruses. Virology 374: 229-233.

Louwagie J, Delwart EL, Mullins JI, McCutchan FE, Eddy G, Burke DS 1994. Genetic analysis of HIV-1 isolates from Brazil reveals presence of two distinct genetic subtypes. AIDS Res Hum Retroviruses 10: 561-567.

Morgado MG, Guimarães ML, Neves Jr I, dos Santos VGV, Linharesde-Carvalho MI, Castello-Branco LR, Bastos FI, Castilho EA, Galvão-Castro B, Bongertz V, The Hospital Evandro Chagas AIDS Clinical Research Group 1998. Molecular epidemiology of
HIV in Brazil: polymorphism of the antigenically distinct HIV-1 B subtype strains. Mem Inst Oswaldo Cruz 93: 383-386.

Morgado MG, Sabino EC, Shpaer EG, Bongertz V, Brigido L, Guimaraes MD, Castilho EA, Galvão-Castro B, Mullins JI, Hendry RM 1994. V3 region polymorphisms in HIV-1 from Brazil: prevalence of subtype B strains divergent from North American/ European prototype and detection of subtype F. AIDS Res Hum Retroviruses 10: 569-576.

MS - Ministério da Saúde 2012. Boletim Epidemiológico AIDSDST. Available from: aids.gov.br/sites/default/files/anexos/ publicacao/2012/52654/boletim_jornalistas_pdf_22172.pdf.

Pilotto JHS, Grinztejn B, Veloso VG, Velasque L, Friedman RK, Moreira RI, Rodrigues-Pedro A, Oliveira SM, Currier J, Morgado MG 2012. Moderate prevalence of transmitted drug-resistance mutations among antiretroviral-naïve HIV-infected pregnant women in Rio de Janeiro, Brazil. AIDS Res Hum Retroviruses 29: 1-6.

Pimentel VF, Morgado MG, Guimarães MDC, Castilho E, Veloso VG, Gimarães ML 2011. Temporal trends of the HIV-1 subtype $\mathrm{B}$ among heterosexual and bisexual men in Brazil. Proceedings of the 6th IAS Conference on HIV Pathogenesis, Treatment and Prevention, 17-20 July 2011, International AIDS Society, Rome. Available from: iasociety.org/Abstracts/A200743204.aspx.

Pinto ME, Schrago CG, Miranda AB, Russo CA 2008. A molecular study on the evolution of a subtype B variant frequently found in Brazil. Genet Mol Res 7: 1031-1044.

Potts KE, Kalish ML, Lott T, Orloff G, Luo CC, Bernard MA, Alves CB, Badaro R, Suleiman J, Ferreira O 1993. Genetic heterogeneity of the V3 region of the HIV-1 envelope glycoprotein in Brazil. AIDS 7: 1191-1197.

Santoro-Lopes G, Harrison LEEH, Tavares MD, Xexéo A, Santos CEA, Schechter M, dos Santos AC 2000. HIV disease progression and V3 serotypes in Brazil: is B different from B-Br? AIDS Res Hum Retroviruses 16: 953-958.

Santos AF, Sousa TM, Soares EA, Sanabani S, Martinez AM, Sprinz E, Silveira J, Sabino EC, Tanuri A, Soares MA 2006. Characterization of a new circulating recombinant form comprising HIV-1 subtypes C and B in southern Brazil. AIDS 20: 2011-2019.

Santos LA, Monteiro-Cunha JP, Araujo AF, Brites C, Galvao-Castro B, Alcantara LCJ 2011. Detection of distinct human immunodeficiency virus type 1 circulating recombinant forms in Northeast Brazil. J Med Virol 83: 2066-2072.

Shimizu N, Takeuchi Y, Naruse T, Inagaki M, Moriyama E, Gojobori T, Hoshino H 1992. Six strains of human immunodeficiency virus type 1 isolated in Japan and their molecular phylogeny. $J \mathrm{Mol}$ Evol 35: 329-336.

Soares EA, Santos RP, Pellegrini JA, Sprinz E, Tanuri A, Soares MA 2003. Epidemiologic and molecular characterization of human immunodeficiency virus type 1 in southern Brazil. J Acquir Immune Defic Syndr 34: 520-526.

Tamura K, Peterson D, Peterson N, Stecher G, Nei M, Kumar S 2011. MEGA5: molecular evolutionary genetics analysis using maximum likelihood, evolutionary distance, and maximum parsimony methods. Mol Biol Evol 28: 2731-2739. 